OPEN ACCESS

Edited by:

Caroline Gurvich,

Monash University, Australia

Reviewed by:

Sonia Shenoy,

Manipal Academy of Higher

Education, India

Elizabeth Thomas,

Monash Alfred Psychiatry Research

Centre, Australia

*Correspondence: Diana Cruz-Topete dcruz2@/suhsc.edu

Specialty section

This article was submitted to Women's Mental Health,

a section of the journal

Frontiers in Global Women's Health

Received: 15 September 2020

Accepted: 25 January 2021

Published: 16 February 2021

Citation:

Dhaibar HA and Cruz-Topete D (2021)

Predisposition of Women to

Cardiovascular Diseases: A

Side-Effect of Increased

Glucocorticoid Signaling During the

COVID-19 Pandemic?

Front. Glob. Womens Health

2:606833.

doi: 10.3389/fgwh.2021.606833

\section{Predisposition of Women to Cardiovascular Diseases: A Side-Effect of Increased Glucocorticoid Signaling During the COVID-19 Pandemic?}

\author{
Hemangini A. Dhaibar and Diana Cruz-Topete* \\ Department of Molecular and Cellular Physiology, Center for Cardiovascular Diseases and Sciences, Louisiana State \\ University Health Sciences Center, Shreveport, LA, United States
}

The novel coronavirus disease 2019 (COVID-19) pandemic has created a significant health crisis worldwide. To mitigate this disease's spread, "social distancing" and "shelter in place" have been implemented. While these actions have been critical to controlling the pandemic, they have short- and long-term mental health consequences due to increased stress. There is a strong association between mental stress and cardiovascular disease (CVD). Young women (pre-menopausal) are at high risk of developing CV events in response to mental stress compared to age-matched men. The mechanisms underlying women's increased reactivity and response to stress are mostly unknown. The present review summarizes the known physiological consequences of mental stress in women's CV health and the latest molecular findings of the actions of the primary stress hormones, glucocorticoids, on the CV system. The current data suggest a clear link between psychological stress and heart disease, and women have an increased sensitivity to the harmful effects of stress hormone signaling imbalances. Therefore, it is expected that with the given unprecedented levels of stress associated with the COVID-19 pandemic, women's CV health will be significantly compromised. It is critical to widen our understanding of the direct contribution of mental stress to CVD risk in women and to identify biochemical markers with predictive value for CVD in female patients with/without cardiovascular conditions who have experienced significant mental stress during the current pandemic.

Keywords: COVID-19, pandemic, women, cardiovascular risk, stress, glucocorticoids, heart

\section{INTRODUCTION}

An outbreak of a novel coronavirus that started in December 2019 in Wuhan, China, has resulted in a horrifying pandemic (1). Worldwide, the health and economic effects of the coronavirus disease 2019 (COVID-19) have been exacerbated for women, in particular for young-middle aged women, who are struggling to combine their professional and family responsibilities (2-4). Disparities in job security, wages, and social pressure to stay home to care for children and older family members have significantly heightened psychological and physical pressure for women as compared to their 
male counterparts (5). Moreover, with the deepening pandemic situation, the restricted movement and social isolation measures have led to an exponential increase in gender-based violence (6). Therefore, women are currently suffering from an unprecedented level of psychological and physical stress.

Exposure to acute and chronic mental stress has been associated with an increase in the causation of pathological conditions for both men and women; however, women are more susceptible to the deleterious effects of stress compared to men $(7,8)$. Depression and anxiety are associated with an increased incidence of obesity, autoimmune disorders, and atherosclerosis in women (9). Clinical studies have highlighted the connection between elevated mental stress and adverse cardiovascular events in women, including myocardial ischemia (MI) and stroke (10-12). Mental stress-induced MI (MSIMI) is twice as common in women under 50 years old than similarly aged men (13). Moreover, among patients with coronary artery diseases (CAD), women, especially younger women, are more likely to develop MSIMI than men, despite less severe obstructive $\mathrm{CAD}$ and a relatively similar profile of traditional CAD risk factors (14). Despite these mentioned clinical evidences, the molecular pathways underlying the deleterious effects of stress in women are unknown. In the present review, we summarize the known sex-specific molecular and physiological effects of stress (crosstalk between sex and stress hormones) on the cardiovascular system and discuss the clinical manifestations of mental stress on the female heart. We also review the potential implications of the elevated mental stress associated with the COVID-19 pandemic in context of future cardiovascular risks in women.

\section{STRESS HORMONE SIGNALING AND PHYSIOLOGICAL EFFECTS}

Any stimulus, intrinsic or extrinsic, that evokes a biological response can be considered as stress (15). These stress stimulating factors can be environmental, inflammatory, psychological, or physical. Exposure to stress leads to the activation of the hypothalamic-pituitary-adrenal (HPA) axis. The effect of stress on the central nervous system (CNS) was first demonstrated in 1968 when studies by Bruce McEwen showed the effects of adrenal hormones on reconfiguring network connections on the brain (16). McEwen's work provided a direct evidence of the chronic effects of cortisol (primary stress hormones in humans) on mental function regulation and coined the term "allostatic load" as the process by which the body prepares and responds to stress to restore homeostasis. His work demonstrated that chronic exposure to stress lead to major changes in neuronal network connections that triggered a neuroendocrine response associated with multi-organ effects (17). McEwen's pioneer work also indicated that chronic stress exposure contributed to neurodegenerative diseases and that stress had sex-specific effects on the CNS (17). The classic primary endocrine mechanism of a body in response to stress encompasses the production of glucocorticoids.

\section{Regulation of Glucocorticoid Secretion and Molecular Signaling}

Glucocorticoids are steroid hormones that are essential for life and are synthesized in the adrenal cortex in response to signals from the hypothalamus (Figure 1). Stress stimulates the paraventricular cells in the hypothalamus to produce the corticotropin-releasing hormone (CRH). $\mathrm{CRH}$ is then released into the pituitary portal vein that stimulates corticotrophs in the anterior pituitary gland for the synthesis and release of adrenocorticotropic hormone (ACTH). ACTH then binds to $G$ protein-coupled receptors located on the zona fasciculata and zona reticularis of the adrenal cortex, which then leads to an increase in intracellular cyclic adenosine monophosphate (cAMP) and activation of protein kinase A (PKA). PKA in turn phosphorylates and induces hormone-sensitive lipase to hydrolyze cholesteryl esters into cholesterol (18) as well as activates the steroidogenic acute regulatory protein (StAR) (1921 ), which then transports cholesterol into the mitochondria, where glucocorticoids are synthesized in a process known as steroidogenesis.

Chronic production of high levels of cortisol results in Cushing syndrome, also known as hypercortisolism (22), while insufficient amounts of adrenal hormones (cortisol, or cortisol and aldosterone) can lead to Addison's disease (23). Both of these conditions involve the dysfunction of HPA axis signaling and have been linked to immune, metabolic, cardiovascular, and mental conditions such as melancholic depression and chronic anxiety $(24,25)$. Therefore, tight control of glucocorticoid secretion is critical to maintain homeostasis. Glucocorticoid levels are regulated by a negative feedback loop at the level of the hypothalamus and pituitary gland. Following the hormone secretion, bioavailability of glucocorticoid is regulated by binding to corticosteroid-binding globulins (CBGs). It is estimated that $80 \%$ of circulating cortisol is bound to CBGs (26). At target tissues, glucocorticoid availability is further modulated by the action of two enzymes: $11 \beta$-hydroxysteroid dehydrogenase type $2(11 \beta H S D 2)$ which oxidizes cortisol into the inactive metabolite cortisone, whereas $11 \beta$-hydroxysteroid dehydrogenase type 1 (11ßHSD1) converts cortisone to cortisol (Figure 1). After release from CBGs, free glucocorticoids can diffuse through the cell membrane, and, once inside the cell, glucocorticoids bind their receptor, the glucocorticoid receptor (GR, NR3C1) (Figure 1).

Glucocorticoid receptor (GR, NR3C1) is a member of the nuclear receptor family of ligand-activated transcription factors, which is expressed in almost every cell in the body (27). Binding of glucocorticoids to GR results in the receptor-glucocorticoid complex translocation into the cell nucleus where GR directly (biding to DNA) or indirectly (interaction with other transcription factors) regulate the expression of target genes (28). Glucocorticoids via GR binding can regulate a vast array of genes involved in controlling the development, metabolism, immune response, and the cardiovascular system (29). Endogenous and some synthetic glucocorticoids can also bind to closely related mineralocorticoid receptor (MR, NR3C2), which is not as widely expressed as the 


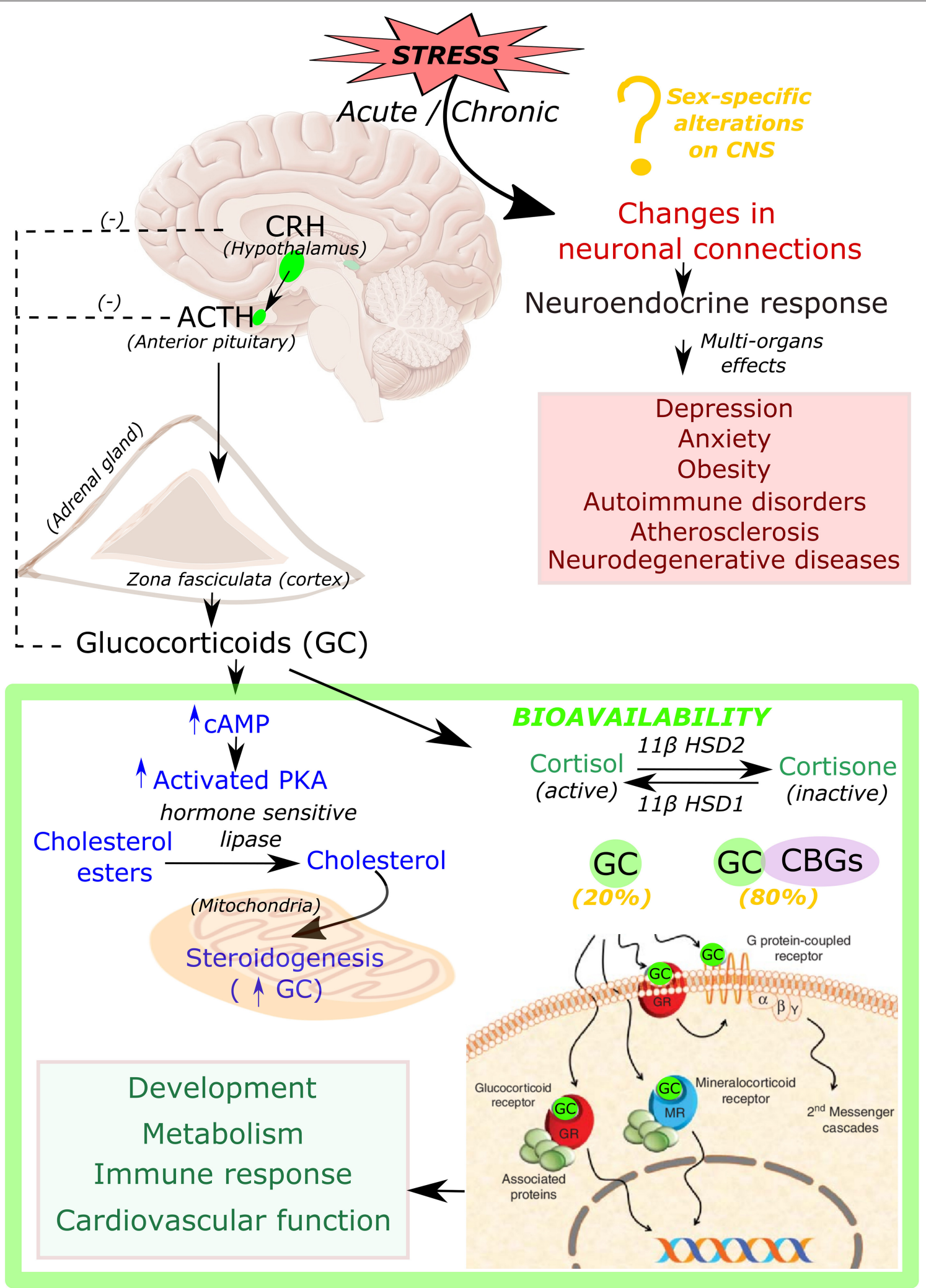

FIGURE 1 | Synthesis, bioavailability and role of glucocorticoid hormone in response to stress. Acute and chronic exposure to stress stimulate hypothalamus to release corticotropin releasing hormone $(\mathrm{CRH})$. $\mathrm{CRH}$ then triggers the secretion of the adrenocorticotrophic hormone $(\mathrm{ACTH})$ from the anterior pituitary gland, which 
FIGURE 1 | binds to its receptors located on the cortex of the adrenal gland that leads to production of intracellular cyclic adenine monophosphate (CAMP). cAMP then activates protein kinase A (PKA). This activated PKA phosphorylate CAMP response element-binding protein (CREB), eventually promotes production of steroidogenic proteins that transport cholesterol into the mitochondria, where glucocorticoids (GC) are synthesized (steroidogenesis). Biologically active form of GC is present in the unbound form (20\%), whereas $80 \%$ remains in inactive condition bound to corticosteroid-binding globulin (CBGs). Free active GC binds to glucocorticoid receptor (GR) or mineralocorticoid receptor (MR) which leads to further downstream signaling responsible for many physiological processes such as development, metabolism, immune response, and cardiovascular function. Chronic stress also leads to changes in many neuronal connections leading to pathological conditions such as depression, anxiety, obesity, autoimmune disorders, atherosclerosis as well as neurodegenerative diseases.

GR, but high levels of MR has been observed in cardiovascular tissue (30). The main ligand for MR is aldosterone. However, giving the fact that cortisol circulates at $\sim 100$ times higher concentrations than aldosterone, in certain tissues that lack $11 \beta$ HSD2, glucocorticoids have been found to significantly occupy MR (30). In the context of the cardiovascular system, glucocorticoid activation of GR has been found to be beneficial for the body to restore homeostasis; however, binding to MR has been shown to exacerbate cardiac dysfunction and failure (31). However, no studies have been performed to evaluate the sex-specific effects of glucocorticoids signaling through MR or GR. The structure and function of the GR gene and protein, and mechanisms of gene regulation are discussed in detail in a recent review by Scheschowitsch et al. (32).

\section{Glucocorticoids and the Cardiovascular System}

Glucocorticoids have positive effects on the cardiovascular (CV) system. Treatment with synthetic glucocorticoids can provide beneficial therapeutic effects on conditions such as myocarditis, cardiac conduction defects, as well as vascular conditions such as angina and acute myocardial infarction (33). However, due to the existence of severe side effects in off-target organ systems, the therapeutic use of glucocorticoids is limited.

In normal physiology, both excesses, and deficiencies of glucocorticoids can lead to cardiovascular disease (CVD) (34). Hypertension and cardiomyopathies are commonly found in Cushing Syndrome patients $(35,36)$. However, hypotension and cardiac dysfunction are regarded as signs of cortisol insufficiency. Polymorphisms of the GR gene are also reported to influence the progress and prognosis of CVD in humans (37-44). The actions of glucocorticoids on the vasculature and the heart are summarized in Figure 2.

In the vascular system, glucocorticoids have been shown to be involved in blood pressure regulation through the modulation of inflammatory and oxidative stress molecular pathways $(29,44-$ 46). In addition, as discussed above, glucocorticoids have been confirmed as vital hormones in the regulation of blood pressure (BP) $(36,47)$, and there is strong evidence that GR is present in both vascular smooth muscle (VSM) (47) and endothelial cells (48). Also, clinical and animal studies have shown that glucocorticoid signaling is critical in the heart (31, 33, 36, 49-52). Antenatal exposure to glucocorticoids increases the expression of endothelial nitric oxide synthase (eNOS, critical for the production of nitric oxide, which is one of the most important endogenous vasodilators) in the large vessel endothelium, large airway, and small airway epithelium of fetal rat lungs $(53,54)$. In adult animal models, exogenous glucocorticoid administration leads to hypertension by suppressing nitric oxide synthase III (NOS) and inducible nitric oxide synthase (iNOS) expression (47, 55-57). Glucocorticoid treatment also inhibits nitric oxide (NO) biosynthesis in the endothelium (48). In addition, glucocorticoids increase the expression of angiotensin II type I receptors in smooth muscle cells, and the influx of $\mathrm{Na}^{+}$and $\mathrm{Ca}^{2+}$ into vascular smooth muscle affects contractility and therefore leads to alterations in blood pressure (58). Moreover, glucocorticoids are known to exert actions on the vasculature by their effects on immune cells, including on macrophages, dendritic cells, and neutrophils $(29,59-62)$. It is still controversial whether glucocorticoids' actions on the vasculature are mediated through GR or MR. Future studies are needed to fully elucidate if glucocorticoids can contribute to hypertension via GR or MR.

In the last decade, a number of studies have been focused on understanding the direct effects of glucocorticoid signaling on the heart. Studies have shown that glucocorticoids signaling through GR or MR play a critical role in regulating cardiac function in health and disease (63). In addition, glucocorticoid signaling through GR contributes to heart development. Using mouse models lacking GR in cardiomyocytes and vascular smooth muscle cells indicated that structural, functional, and biochemical maturation of the fetal heart is dependent on intact glucocorticoid signaling (64). Studies on adult mice with cardiomyocyte GR deficiency have also exhibited that an intact glucocorticoid signal is critical for the regulation of systolic function in a post-natal heart. Cardiomyocyte GR deficiency in adult mice leads to early death due to pathological cardiac hypertrophy that progresses to dilated cardiomyopathy and heart failure (50). These effects seem to be associated with the GR regulation of genes involved in cardiac contractility (ryanodine receptors 2, RyR2), cardiomyocyte survival (prostaglandin D2 synthase, Ptgds), and the inhibition of inflammation (lipocalin 2, Lcn 2) (50). MR deficiency does not lead to any major structural or functional abnormalities, and it seems to be protective against myocardial injury $(65,66)$. GR overexpression in the heart leads to bradycardia and a chronic atrioventricular block in mice (49) but not arrhythmia or premature death. In contrast, MR overexpression and increased signaling in the heart leads to major ECG abnormalities, cardiac arrhythmias, dysregulation in $\mathrm{Na}^{+}$and $\mathrm{K}^{+}$currents, and a high death rate (67). Whether glucocorticoid effects in the heart are mediated via GR or MR is a topic of controversy. However, recent novel studies by Oakley et al. (31) provide direct evidence that glucocorticoid signaling through MR in the absence of GR in cardiomyocytes seems to mediate most of the negative effects of glucocorticoids in the heart. Glucocorticoids signaling via cardiomyocyte MR leads to cardiac pathology, whereas glucocorticoids signaling through GR 


\section{GLUCOCORTICOIDS}

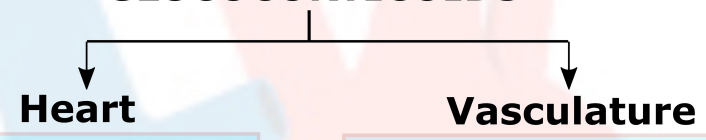

Restore Homeostasis Heart development

Systolic function

Cardiac contractility

Cardiomyocyte survival

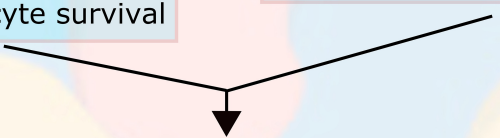

Modulation of inflammatory and oxidative pathways eNOS, iNOS and nNOS regulation

NO biosynthesis

Carbohydrate metabolism

Lipid metabolism

Expression of Angiotensin II type I receptors I (SM)

Cardiac contractility (Influx of $\mathrm{Na}^{+}$and $\mathrm{K}^{+}$in vascular SM)

Action on immune cells (Macrophages, Dentritic cells and Neutrophils)

I

Excess/Deficiencies of GCs

Genetic polymorphisms of GR

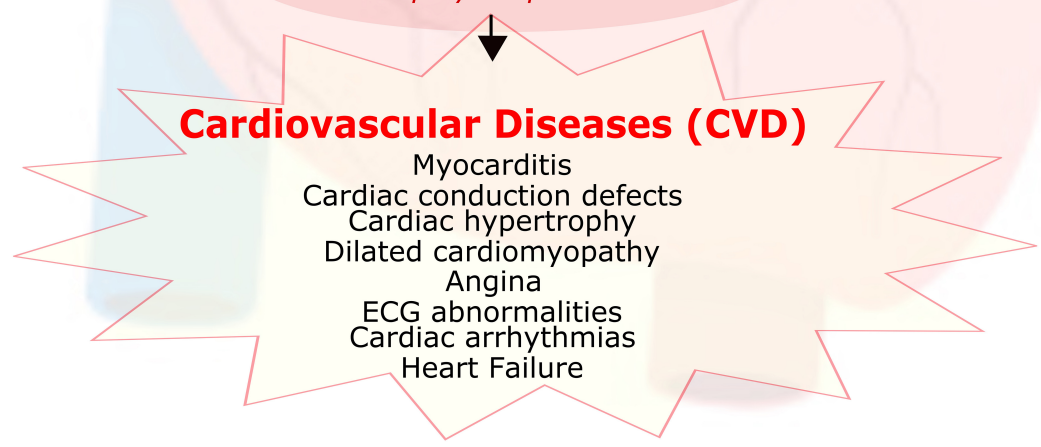

FIGURE 2 | Essential role of glucocorticoids in cardiovascular function. Glucocorticoids (GC) play an essential role in heart and vasculature. It is involved in signaling important functions such as maintaining the cardiac homeostasis, cardiac development, cardiac contractility, cardiac rhythm, modulation of inflammation and oxidative stress, cardiomyocyte survival, carbohydrate and lipid metabolism, inhibiting nitric oxide (NO) biosynthesis, modulating expression of angiotensin II type I receptors on smooth muscle cells (SM) as well as interaction with immune cells (macrophages, dendritic cells and neutrophils). Abnormal function of (GC) due to its excess/deficiencies or due to genetic polymorphism in its receptor leads to many cardiovascular diseases. GC, glucocorticoids; GR, glucocorticoid receptors; eNOS, endothelial nitric oxide synthase; iNOS, inducible nitric oxide synthase; nNOS, neuronal nitric oxide synthase; SNS, sympathetic nervous system; ECG. electrocardiogram.

have been observed to be cardioprotective. Thus, these results suggest that the balance between GR and MR is critical in heart disease. However, it remains to be clarified whether the effects of glucocorticoid signaling on the heart are sexually dimorphic.

\section{Glucocorticoid Signaling Cross-Talk With Sex Hormones}

The sexually dimorphic actions of glucocorticoid regulation of gene expression were observed to contribute to the dimorphic basis of inflammatory disease in a study by Duma et al. (68). In this study, comparison of number of genes involved in inflammatory disorders between sexes revealed that glucocorticoids have more profound anti-inflammatory effects on males as compared to females, suggesting that females have additional factors that may inhibit/alter the response to glucocorticoids (68).

GR exhibits female-biased expression in several preoptic and thalamic nuclei, thus indicating that glucocorticoids have a greater influence on physiology and behavior, mediated by specific neuropeptides more so in females than in males (69). Since the brain plays an important role in governing the stress response, this may contribute to gender differences in $\mathrm{CV}$ response to stress. The $\mathrm{CV}$ system is susceptible to emotional stress, and young and middle-aged women appear to be 
especially vulnerable to psychosocial risk factors $(11,13,70-72)$. Depression, trauma, and perceived stress are disproportionately common in women as compared to their male counterparts or older patients and can be considered predictors of CV risk (14, 73-75). However, no studies have been performed to investigate whether exposure to severe mental stress for a considerable period of time leads to irreversible gene programming and epigenetic changes that predispose or increase the risk for $\mathrm{CV}$ complications, despite going back to a period of "normal" stress levels.

Regarding the sexual dimorphic effects of glucocorticoid on the heart, animal studies have demonstrated that the deletion of GR in cardiomyocytes leads to systolic dysfunction and heart failure in both male and female mice (52). However, this phenotype appears early in males as compared to females and is associated with dysregulation of different cardiac gene networks (52). These differences may arise from the effects of sex hormones on the heart. Ovarian hormone (in particular, estrogen) signaling may be compensating initially for the lack of GR in the heart, whereas androgens may be exacerbating the deleterious effects of GR deficiency in cardiomyocytes $(52,68,69,76-78)$. Future studies are needed to fully elucidate the mechanisms behind the sex differences in the physiological consequences of GR signaling in the heart. However, more work is needed to clarify whether glucocorticoid signaling in heart results from GR crosstalk with androgen receptors (AR) or estrogen receptor (ER) signaling and whether if these interactions play a role in male and female differential sensitivity to the effects of exposure to higher stress levels as it relates to cardiovascular and heart disease. Moreover, studies are needed to further define the role of MR in glucocorticoids' sex-specific effects on the heart.

In addition, chronic stress has been shown to increase the risk of hypertension for both men and women $(79,80)$. Most studies have associated stress and hypertension with the stimulation of the sympathetic nervous system response, in which the release of catecholamines leads to increased heart rate, cardiac output, and altered blood pressure (80). However, future studies need to focus on investigating the direct contribution of glucocorticoid release in response to stress in blood pressure regulation, with special emphasis on characterizing the gender-specific effects of chronic stress and pathological hypertension.

In the next section, we briefly discuss how trauma-related mental health disorders during the COVID-19 pandemic might alter glucocorticoid signaling in the female heart, and the potential CV side-effects of the increased activation of GR signaling associated with the COVID-19 pandemic for women.

\section{THE PRICE OF THE COVID-19 PANDEMIC ASSOCIATED STRESS ON WOMEN'S CV HEALTH}

The COVID-19 pandemic has led to unprecedented levels of mental and emotional stress (81). The uncertainty due to the fear of infection, economic losses, and isolation due to quarantining has triggered a substantial decline in mental health for both men and women. However, women's mental health appears to be disproportionally affected. Emerging data show that women are suffering more than men from the pandemic-associated stressors, and that there is a higher self-reported symptoms of anxiety, depression, post-traumatic stress disorder, and poor psychological well-being in them (82-85). Moreover, since women are already at a higher risk for depressive and anxiety disorders, the current environmental stress has intensified the severity of these disorders for women (86).

There is a strong association between psychological stress and cardiovascular disease (70,87-90). Exposure to stressors such as natural disasters has demonstrated an increase in cardiovascular risk associated with prolonged emotional trauma due to human and economic losses and changes in the daily routine. Studies show that sudden changes in heart rate and increases in blood pressure are common in populations that have experienced an earthquake and are facing uncertainty $(90,91)$. Moreover, a dramatic increase in pulmonary embolism and myocardial infarction (MI) has been observed in the wake of an earthquake (91). Similarly, other natural disasters, such as hurricanes, floods and tsunamis, that disrupt the fully functioning lives of the victims and cause loss for individuals, families and communities have highlighted the association between CVD risk and mental stress $(92,93)$. A recent study also revealed that the number of trauma-related mental health disorders has increased significantly during COVID-19 quarantine $(83,94)$. Therefore, a substantial increase in mental health conditions and associated sequelae is expected to be a consequence of this pandemic worldwide. Given the link between mental stress and CVD risk, it is critical to investigate the biological pathways underlying the stress response and the CV system to identify patients at risk (prevention) and to discover novel therapeutic targets.

Traditionally, it has been assumed that premenopausal women have a lower cardiac risk than men (95). This decreased risk has been attributed to estrogen, which has anti-atherosclerotic effects (96-98). Data from the Framingham Heart Study suggested a strong association between low estrogen levels (menopause) and increased cardiovascular risk in women (99). However, while some studies show that low estrogen dose therapy has been shown to be beneficial for cardiovascular health in post-menopausal women (100), the data remain controversial regarding whether long-term estrogen therapy improves cardiovascular outcomes for women (101). Moreover, recent clinical evidence has also shown that although there has been a decrease in heart disease mortality for both men and women over 65 years of age in the last three decades, the incidence of cardiovascular events has significantly increased among premenopausal women (102). These results suggest that additional risk factors have a differential impact on women's cardiovascular health compared to men.

Women differ from men in a multitude of ways (Figure 3), including genetic differences in immunity $(103,104)$, coagulation $(105,106)$, and hormonal factors (107), all of which can influence the risk for CVD and related outcomes. Many studies have highlighted sex differences in delayed hospital arrival and lack of sufficient awareness of women in the context of CVD $(108,109)$. Along with these factors that has been associated with increased mortality for women, abnormal levels 


\section{A}

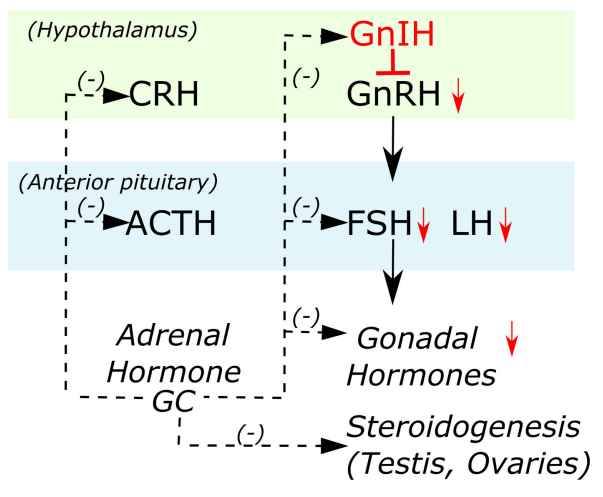

B

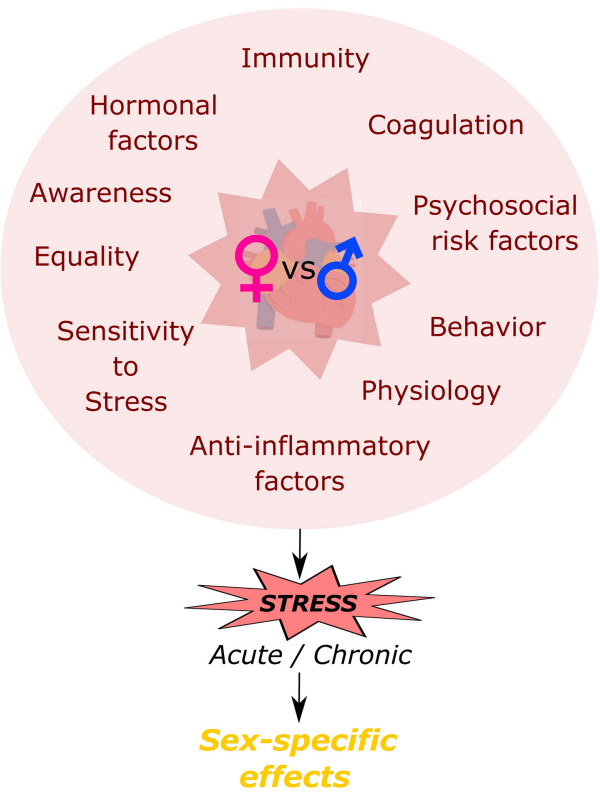

FIGURE 3 | Inter-relationship of different factors responsible in causation of sex-specific effects to stress. (A) Interactions among the hypothalamo-pituitary-adrenal (HPA) and hypothalamo-pituitary-gonal (HPA) axes by glucocorticoid hormone (GC). (B) Different factors influencing female's cardiac health compared to males in developing a sex-specific effect in response to stress.

of glucocorticoids have also been known to increase CV risk for women $(7,11,75,110-112)$. However, surprisingly, very little has been explored about the direct role of glucocorticoid signaling on the female heart.

\section{CONCLUSIONS AND FUTURE PERSPECTIVES}

The COVID-19 pandemic has exponentially raised anxiety and depression in vulnerable populations due to economic and social pressure, uncertainty, isolation, and feelings of immobility/constraint due to social distancing measures. Young and middle-aged women are among the most affected due to the lack of balance between demanding job schedules and family responsibilities.

The mechanisms responsible for the sex-specific effects of stress hormones on the CV system are still unclear. Women have an increased vascular reactivity to glucocorticoids, which may account for their increased risk of mental-stress-induced ischemia $(73,113)$. However, the molecular pathways underlying this reactivity are unknown. A potential mechanism for the sexspecific effects of stress is the crosstalk between glucocorticoids and sex-hormones signaling. A better understanding of such interactions will open up new potential avenues for risk assessment and prevention for women. It will be particularly be important to study whether exposure to chronic mental stress for a period of time leads to gene reprogramming that may predispose women to $\mathrm{CV}$ complications, exacerbate the effects of additional comorbidities, and negatively impact the aging process. Assessment of mental health status, in addition to traditional risk factors, has become more important than ever. There is a clear connection between psychological stress and heart disease and understanding this connection will aid in preventing and improving cardiovascular outcomes for the general population and women.

\section{AUTHOR CONTRIBUTIONS}

All authors contributed to writing the manuscript, critically revised the work, and approved the final version.

\section{FUNDING}

This research was supported by the Molecular and Cellular Physiology Department (HD and DC-T), COVID-19 Intramural grant Cardiovascular Diseases and Sciences LSU HSC Shreveport (HD and DC-T), NIH: P20GM121307, K01 HL144882-01A1 (DC-T).

\section{ACKNOWLEDGMENTS}

We would like to extend our apologies to all our colleagues whose work we were unable to cite owing to space limitations. We would like to thank and acknowledge these individuals for their contributions to grow our understanding of the effects of stress on the cardiovascular system. 


\section{REFERENCES}

1. Cutler DM, Summers LH. The COVID-19 pandemic and the $\$ 16$ trillion virus. JAMA. (2020) 324:1495. doi: 10.1001/jama.2020.19759

2. Ayaz R, Hocaoglu M, Günay T, Yardimc, OD, Turgut A, Karateke A. Anxiety and depression symptoms in the same pregnant women before and during the COVID-19 pandemic. J Perinat Med. (2020) 48:965-70. doi: 10.1515/jpm-2020-0380

3. Gulati G, Kelly BD. Domestic violence against women and the COVID19 pandemic: what is the role of psychiatry? Int J Law Psychiatry. (2020) 71:101594. doi: 10.1016/j.ijlp.2020.101594

4. Marques ES, Moraes CL, de Hasselmann MH, Deslandes SF, Reichenheim ME, Marques ES, et al. Violence against women, children, and adolescents during the COVID-19 pandemic: overview, contributing factors, and mitigating measures. Cad Saúde Pública. (2020) 36:e00074420. doi: 10.1590/0102-311x00074420

5. Women at the Core of the Fight Against COVID-19 Crisis. OECD (2020). Available online at: https://read.oecd-ilibrary.org/view/?ref=127_127000awfnqj80me\&title=Women- at- the- core- of-the-fight- against-COVID-19crisis (accessed July 31, 2020).

6. UN Women | Explainer: How COVID-19 Impacts Women and Girls. UN Women (2020). Available online at: https://www.unwomen.org/en/ digital-library/multimedia/2020/5/explainer-covid19-impacts-women-girls (accessed August 3, 2020).

7. Vaccarino V. Sex and gender medicine: how women's heart is vulnerable. $G$ Ital Cardiol. (2012) 13:382-5. doi: 10.1714/1073.11754

8. Mehta PK, Bess C, Elias-Smale S, Vaccarino V, Quyyumi A, Pepine CJ, et al. Gender in cardiovascular medicine: chest pain and coronary artery disease. Eur Heart J. (2019) 40:3819-26. doi: 10.1093/eurheartj/ehz784

9. Kadmiel M, Cidlowski JA. Glucocorticoid receptor signaling in health and disease. Trends Pharmacol Sci. (2013) 34:518-30. doi: 10.1016/j.tips.2013.07.003

10. Strike PC, Steptoe A. Systematic review of mental stressinduced myocardial ischaemia. Eur Heart J. (2003) 24:690-703. doi: 10.1016/S0195-668X(02)00615-2

11. Linke SE, Rutledge T, Johnson BD, Vaccarino V, Bittner V, Cornell CE, et al. Depressive symptom dimensions and cardiovascular prognosis among women with suspected myocardial ischemia: a report from the national heart, lung, and blood institute-sponsored women's ischemia syndrome evaluation. Arch Gen Psychiatry. (2009) 66:499-507. doi: 10.1001/archgenpsychiatry.2009.27

12. Wei J, Rooks C, Ramadan R, Shah AJ, Bremner JD, Quyyumi AA, et al. Metaanalysis of mental stress-induced myocardial ischemia and subsequent cardiac events in patients with coronary artery disease. Am J Cardiol. (2014) 114:187-92. doi: 10.1016/j.amjcard.2014.04.022

13. Vaccarino V, Shah AJ, Rooks C, Ibeanu I, Nye JA, Pimple P, et al. Sex differences in mental stress-induced myocardial ischemia in young survivors of an acute myocardial infarction. Psychosom Med. (2014) 76:171-80. doi: 10.1097/PSY.0000000000000045

14. Vaccarino V, Sullivan S, Hammadah M, Wilmot K, Al Mheid I, Ramadan $\mathrm{R}$, et al. Mental stress-induced-myocardial ischemia in young patients with recent myocardial infarction: sex differences and mechanisms. Circulation. (2018) 137:794-805. doi: 10.1161/CIRCULATIONAHA.117.0 30849

15. Yaribeygi H, Panahi Y, Sahraei H, Johnston TP, Sahebkar A. The impact of stress on body function: a review. EXCLI J. (2017) 16:1057-72. doi: 10.17179/excli2017-480

16. McEwen BS, Stellar E. Stress and the individual. Mechanisms leading to disease. Arch Intern Med. (1993) 153:2093-101. doi: 10.1001/archinte.1993.00410180039004

17. McEwen BS, Gray JD, Nasca C. Recognizing resilience: learning from the effects of stress on the brain. Neurobiol Stress. (2014) 1:1-11. doi: 10.1016/j.ynstr.2014.09.001

18. Allen MJ, Sharma S. Physiology, Adrenocorticotropic Hormone (ACTH). In StatPearls. Treasure Island, FL: StatPearls Publishing (2020). Available online at: http://www.ncbi.nlm.nih.gov/books/NBK500031/ (accessed September 8, 2020).
19. Kraemer FB, Shen WJ. Hormone-sensitive lipase: control of intracellular tri-(di-)acylglycerol and cholesteryl ester hydrolysis. J Lipid Res. (2002) 43:1585-94. doi: 10.1194/jlr.R200009-JLR200

20. Kraemer FB, Shen WJ, Natu V, Patel S, Osuga J, Ishibashi S, et al. Adrenal neutral cholesteryl ester hydrolase: identification, subcellular distribution, and sex differences. Endocrinology. (2002) 143:801-6. doi: 10.1210/endo.143.3.8693

21. Miller WL. Steroidogenic acute regulatory protein (StAR), a novel mitochondrial cholesterol transporter. Biochim Biophys Acta. (2007) 1771:663-76. doi: 10.1016/j.bbalip.2007.02.012

22. Nieman LK. Cushing's syndrome: update on signs, symptoms and biochemical screening. Eur J Endocrinol. (2015) 173:M33-8. doi: 10.1530/EJE-15-0464

23. Nieman LK, Chanco Turner ML. Addison's disease. Clin Dermatol. (2006) 24:276-80. doi: 10.1016/j.clindermatol.2006.04.006

24. Fava GA, Sonino N, Morphy MA. Major depression associated with endocrine disease. Psychiatr Dev. (1987) 5:321-48.

25. Daniels J, Turner-Cobb JM. Adjuvant psychological therapy in long-term endocrine conditions. Clin Endocrinol. (2017) 86:772-7. doi: $10.1111 /$ cen.13341

26. Hammond GL. Plasma steroid-binding proteins: primary gatekeepers of steroid hormone action. J Endocrinol. (2016) 230:R13-25. doi: 10.1530/JOE-16-0070

27. Pujols L, Mullol J, Roca-Ferrer J, Torrego A, Xaubet A, Cidlowski $\mathrm{JA}$, et al. Expression of glucocorticoid receptor $\alpha$ - and $\beta$-isoforms in human cells and tissues. Am J Physiol Cell Physiol. (2002) 283:C1324-31. doi: 10.1152/ajpcell.00363.2001

28. Oakley RH, Cidlowski JA. The biology of the glucocorticoid receptor: new signaling mechanisms in health and disease. J Allergy Clin Immunol. (2013) 132:1033-44. doi: 10.1016/j.jaci.2013.09.007

29. Barnes PJ. Anti-inflammatory actions of glucocorticoids: molecular mechanisms. Clin Sci. (1998) 94:557-72. doi: 10.1042/cs0940557

30. Oakley RH, Cidlowski JA. Glucocorticoid signaling in the heart: a cardiomyocyte perspective. J Steroid Biochem Mol Biol. (2015) 153:27-34. doi: 10.1016/j.jsbmb.2015.03.009

31. Oakley RH, Cruz-Topete D, He B, Foley JF, Myers PH, Xu X, et al. Cardiomyocyte glucocorticoid and mineralocorticoid receptors directly and antagonistically regulate heart disease in mice. Sci Signal. (2019) 12:eaau9685. doi: 10.1126/scisignal.aau 9685

32. Scheschowitsch K, Leite JA, Assreuy J. New insights in glucocorticoid receptor signaling - more than just a ligand binding receptor. Front Endocrinol. (2017) 8:16. doi: 10.3389/fendo.2017.00016

33. Nussinovitch U, de Carvalho JF, Pereira RMR, Shoenfeld Y. Glucocorticoids and the cardiovascular system: state of the art. Curr Pharm Des. (2010) 16:3574-85. doi: 10.2174/138161210793797870

34. Sapolsky RM, Romero LM, Munck AU. How do glucocorticoids influence stress responses? Integrating permissive, suppressive, stimulatory, and preparative actions. Endocr Rev. (2000) 21:55-89. doi: 10.1210/er.21.1.55

35. Whitworth JA. Studies on the mechanisms of glucocorticoid hypertension in humans. Blood Pressure. (1994) 3:24-32. doi: 10.3109/08037059409101518

36. Lee SR, Kim HK, Youm JB, Dizon LA, Song IS, Jeong SH, et al. Nongenomic effect of glucocorticoids on cardiovascular system. Pflugers Arch Eur J Physiol. (2012) 464:549-59. doi: 10.1007/s00424-012-1155-2

37. Ukkola O, Rosmond R, Tremblay A, Bouchard C. Glucocorticoid receptor $\mathrm{Bcl} I$ variant is associated with an increased atherogenic profile in response to long-term overfeeding. Atherosclerosis. (2001) 157:221-4. doi: 10.1016/S0021-9150(00)00712-7

38. Gross KL, Cidlowski JA. Tissue-specific glucocorticoid action: a family affair. Trends Endocrinol Metab. (2008) 19:331-9. doi: 10.1016/j.tem.2008.07.009

39. Koeijvoets KCMC, van der Net JB, van Rossum EFC, Steyerberg EW, Defesche JC, Kastelein JJP, et al. Two common haplotypes of the glucocorticoid receptor gene are associated with increased susceptibility to cardiovascular disease in men with familial hypercholesterolemia. J Clin Endocrinol Metab. (2008) 93:4902-8. doi: 10.1210/jc.2008-0813

40. Hauer D, Weis F, Papassotiropoulos A, Schmoeckel M, Beiras-Fernandez A, Lieke J, et al. Relationship of a common polymorphism of the glucocorticoid receptor gene to traumatic memories and posttraumatic stress disorder 
in patients after intensive care therapy. Crit Care Med. (2011) 39:643-50. doi: 10.1097/CCM.0b013e318206bae6

41. Giordano R, Marzotti S, Berardelli R, Karamouzis I, Brozzetti A, D’Angelo V, et al. BClI polymorphism of the glucocorticoid receptor gene is associated with increased obesity, impaired glucose metabolism and dyslipidaemia in patients with Addison's disease. Clin Endocrinol. (2012) 77:863-70. doi: 10.1111/j.1365-2265.2012.04439.x

42. Steiger $\mathrm{H}$, Gauvin $\mathrm{L}$, Joober R, Israel M, Badawi G, Groleau P, et al. Interaction of the BcII glucocorticoid receptor polymorphism and childhood abuse in bulimia nervosa (BN): Relationship to BN and to associated trait manifestations. J Psychiatr Res. (2012) 46:152-8. doi: 10.1016/j.jpsychires.2011.10.005

43. Kino T. Single nucleotide variations of the human gr gene manifested as pathologic mutations or polymorphisms. Endocrinology. (2018) 159:250619. doi: $10.1210 /$ en.2017-03254

44. Liu B, Zhang TN, Knight JK, Goodwin JE. The glucocorticoid receptor in cardiovascular health and disease. Cells. (2019) 8:1227. doi: $10.3390 /$ cells 8101227

45. Rosmond R, Chagnon YC, Holm G, Chagnon M, Pérusse L, Lindell K, et al. A glucocorticoid receptor gene marker is associated with abdominal obesity, leptin, and dysregulation of the hypothalamic-pituitary-adrenal axis. Obes Res. (2000) 8:211-8. doi: 10.1038/oby.2000.24

46. Sun D, Huang A, Yan EH, Wu Z, Yan C, Kaminski PM, et al. Reduced release of nitric oxide to shear stress in mesenteric arteries of aged rats. Am J Physiol Heart Circ Physiol. (2004) 286:H2249-56. doi: 10.1152/ajpheart.00854.2003

47. Goodwin JE, Zhang J, Geller DS. A critical role for vascular smooth muscle in acute glucocorticoid-induced hypertension. J Am Soc Nephrol. (2008) 19:1291-9. doi: 10.1681/ASN.2007080911

48. Goodwin JE, Feng Y, Velazquez H, Sessa WC. Endothelial glucocorticoid receptor is required for protection against sepsis. Proc Natl Acad Sci USA. (2013) 110:306-11. doi: 10.1073/pnas.1210200110

49. Sainte-Marie Y, Cat AND, Perrier R, Mangin L, Soukaseum C, Peuchmaur $\mathrm{M}$, et al. Conditional glucocorticoid receptor expression in the heart induces atrio-ventricular block. FASEB J. (2007) 21:3133-41. doi: 10.1096/fj.07-8357com

50. Oakley RH, Ren R, Cruz-Topete D, Bird GS, Myers PH, Boyle MC, et al. Essential role of stress hormone signaling in cardiomyocytes for the prevention of heart disease. Proc Natl Acad Sci USA. (2013) 110:17035-40. doi: 10.1073/pnas.1302546110

51. Cruz-Topete D, He B, Xu X, Cidlowski JA. Krüppel-like factor 13 is a major mediator of glucocorticoid receptor signaling in cardiomyocytes and protects these cells from DNA damage and death. J Biol Chem. (2016) 291:19374-86. doi: 10.1074/jbc.M116.725903

52. Cruz-Topete D, Oakley RH, Carroll NG, He B, Myers PH, Xu X, et al. Deletion of the cardiomyocyte glucocorticoid receptor leads to sexually dimorphic changes in cardiac gene expression and progression to heart failure. J Am Heart Assoc. (2019) 8:e011012. doi: 10.1161/JAHA.118.011012

53. Baytur $\mathrm{YB}$, Ozbilgin $\mathrm{K}$, Yuksel $\mathrm{H}$, Kose C. Antenatal administration of granulocyte-macrophage colony-stimulating factor increases fetal lung maturation and endothelial nitric oxide synthase expression in the fetal rat lung. Eur J Obstet Gynecol Reprod Biol. (2008) 136:171-7. doi: 10.1016/j.ejogrb.2007.03.010

54. Chandrasekar I, Eis A, Konduri GG. Betamethasone attenuates oxidant stress in endothelial cells from fetal lambs with persistent pulmonary hypertension. Pediatr Res. (2008) 63:67-72. doi: 10.1203/PDR.0b013e31815b43ee

55. Hafezi-Moghadam A, Simoncini T, Yang Z, Limbourg FP, Plumier JC, Rebsamen MC, et al. Acute cardiovascular protective effects of corticosteroids are mediated by non-transcriptional activation of endothelial nitric oxide synthase. Nat Med. (2002) 8:473-9. doi: 10.1038/nm0502-473

56. Baum M, Moe OW. Glucocorticoid-mediated hypertension: does the vascular smooth muscle hold all the answers? J Am Soc Nephrol. (2008) 19:1251-3. doi: 10.1681/ASN.2008040410

57. Ong SL, Whitworth JA. Glucocorticoid-induced hypertension and the nitric oxide system. Exp Rev Endocrinol Metab. (2012) 7:273-80. doi: 10.1586/eem.12.19

58. Sato A, Suzuki H, Murakami M, Nakazato Y, Iwaita Y, Saruta T. Glucocorticoid increases angiotensin II type 1 receptor and its gene expression. Hypertension. (1994) 23:25-30. doi: 10.1161/01.HYP.23.1.25
59. Ray A, Prefontaine KE. Physical association and functional antagonism between the p65 subunit of transcription factor NF-kappa B and the glucocorticoid receptor. Proc Natl Acad Sci USA. (1994) 91:752-6. doi: 10.1073/pnas.91.2.752

60. Baschant U, Tuckermann J. The role of the glucocorticoid receptor in inflammation and immunity. J Steroid Biochem Mol Biol. (2010) 120:69-75. doi: 10.1016/j.jsbmb.2010.03.058

61. Zhou JY, Zhong HJ, Yang C, Yan J, Wang HY, Jiang JX. Corticosterone exerts immunostimulatory effects on macrophages via endoplasmic reticulum stress. Br J Surg. (2010) 97:281-93. doi: 10.1002/bjs.6820

62. Cruz-Topete D, Cidlowski JA. One hormone, two actions: anti- and proinflammatory effects of glucocorticoids. Neuroimmunomodulation. (2015) 22:20-32. doi: 10.1159/000362724

63. Richardson RV, Batchen EJ, Denvir MA, Gray GA, Chapman KE. Cardiac GR and MR: from development to pathology. Trends Endocrinol Metab. (2016) 27:35-43. doi: 10.1016/j.tem.2015.10.001

64. Rog-Zielinska EA, Thomson A, Kenyon CJ, Brownstein DG, Moran CM, Szumska D, et al. Glucocorticoid receptor is required for foetal heart maturation. Hum Mol Genet. (2013) 22:3269-82. doi: 10.1093/hmg/ddt182

65. Fraccarollo D, Berger S, Galuppo P, Kneitz S, Hein L, Schütz G, et al. Deletion of cardiomyocyte mineralocorticoid receptor ameliorates adverse remodeling after myocardial infarction. Circulation. (2011) 123:400-8. doi: 10.1161/CIRCULATIONAHA.110.983023

66. Lother A, Berger S, Gilsbach R, Rösner S, Ecke A, Barreto F, et al. Ablation of mineralocorticoid receptors in myocytes but not in fibroblasts preserves cardiac function. Hypertension. (2011) 57:746-54. doi: 10.1161/HYPERTENSIONAHA.110.163287

67. Ouvrard-Pascaud A, Sainte-Marie Y, Bénitah JP, Perrier R, Soukaseum C, Nguyen Dinh Cat A, et al. Conditional mineralocorticoid receptor expression in the heart leads to life-threatening arrhythmias. Circulation. (2005) 111:3025-33. doi: 10.1161/CIRCULATIONAHA.104.503706

68. Duma D, Collins JB, Chou JW, Cidlowski JA. Sexually dimorphic actions of glucocorticoids provide a link to inflammatory diseases with gender differences in prevalence. Sci Signal. (2010) 3:ra74. doi: 10.1126/scisignal.2001077

69. Kikuchi Y, Hosono K, Yamashita J, Kawabata Y, Okubo K. Glucocorticoid receptor exhibits sexually dimorphic expression in the medaka brain. Gen Comp Endocrinol. (2015) 223:47-53. doi: 10.1016/j.ygcen.2015.09.031

70. Vaccarino V, Goldberg J, Magruder KM, Forsberg CW, Friedman MJ, Litz BT, et al. Posttraumatic stress disorder and incidence of type-2 diabetes: a prospective twin study. J Psychiatr Res. (2014) 56:158-64. doi: 10.1016/j.jpsychires.2014.05.019

71. Maletic V, Robinson M, Oakes T, Iyengar S, Ball SG, Russell J. Neurobiology of depression: an integrated view of key findings. Int J Clin Pract. (2007) 61:2030-40. doi: 10.1111/j.1742-1241.2007.01602.x

72. Harrewijn A, Vidal-Ribas P, Clore-Gronenborn K, Jackson SM, Pisano S, Pine DS, et al. Associations between brain activity and endogenous and exogenous cortisol - A systematic review. Psychoneuroendocrinology. (2020) 120:104775. doi: 10.1016/j.psyneuen.2020.104775

73. Sullivan S, Hammadah M, Wilmot K, Ramadan R, Pearce BD, Shah A, et al. Young women with coronary artery disease exhibit higher concentrations of interleukin-6 at baseline and in response to mental stress. J Am Heart Assoc. (2018) 7:e010329. doi: 10.1161/JAHA.118.010329

74. Brown KM, Hui Q, Huang Y, Taylor JY, Prescott L, de Mendoza VB, et al. Association between stress and coping with DNA methylation of blood pressure-related genes among african American women. Chronic Stress. (2019) 3:2470547019879088. doi: 10.1177/2470547019 879088

75. Women's Health. CDC(2020). Available online at: https://www.cdc.gov/ women/heart/index.htm (accessed August 22, 2020).

76. Bolt MJ, Stossi F, Newberg JY, Orjalo A, Johansson HE, Mancini MA. Coactivators enable glucocorticoid receptor recruitment to fine-tune estrogen receptor transcriptional responses. Nucleic Acids Res. (2013) 41:4036-48. doi: 10.1093/nar/gkt100

77. Miranda TB, Voss TC, Sung MH, Baek S, John S, Hawkins M, et al. Reprogramming the chromatin landscape: interplay of the estrogen and glucocorticoid receptors at the genomic level. Cancer Res. (2013) 73:5130-9. doi: 10.1158/0008-5472.CAN-13-0742 
78. Hegde SM, Kumar MN, Kavya K, Kumar KMK, Nagesh R, Patil RH, et al. Interplay of nuclear receptors (ER, PR, and GR) and their steroid hormones in MCF-7 cells. Mol Cell Biochem. (2016) 422:109-20. doi: 10.1007/s11010-016-2810-2

79. Boese AC, Kim SC, Yin KJ, Lee JP, Hamblin MH. Sex differences in vascular physiology and pathophysiology: estrogen and androgen signaling in health and disease. Am J Physiol Heart Circ Physiol. (2017) 313:H524-45. doi: 10.1152/ajpheart.00217.2016

80. Spruill Tanya M, Butler Mark J, Thomas S, Justin, Tajeu Gabriel S, Kalinowski J, Castañeda Sheila F, et al. Association between high perceived stress over time and incident hypertension in black adults: findings from the jackson heart study. J Am Heart Assoc. (2019) 8:e012139. doi: 10.1161/JAHA.119.012139

81. O'Neil A, Nicholls SJ, Redfern J, Brown A, Hare DL. Mental health and psychosocial challenges in the COVID-19 pandemic: food for thought for cardiovascular health care professionals. Heart Lung Circ. (2020) 29:960-3. doi: 10.1016/j.hlc.2020.05.002

82. Almeida M, Shrestha AD, Stojanac D, Miller LJ. The impact of the COVID19 pandemic on women's mental health. Arch Womens Ment Health. (2020) 23:741-8.. doi: 10.1007/s00737-020-01092-2

83. Liu N, Zhang F, Wei C, Jia Y, Shang Z, Sun L, et al. Prevalence and predictors of PTSS during COVID-19 outbreak in China hardesthit areas: Gender differences matter. Psychiatry Res. (2020) 287:112921. doi: 10.1016/j.psychres.2020.112921

84. Minello A. The pandemic and the female academic. Nature. (2020). doi: 10.1038/d41586-020-01135-9. [Epub ahead of print].

85. Wang C, Pan R, Wan X, Tan Y, Xu L, Ho CS, et al. Immediate psychological responses and associated factors during the initial stage of the 2019 coronavirus disease (COVID-19) epidemic among the general population in China. Int J Environ Res Public Health. (2020) 17:1729. doi: 10.3390/ijerph17051729

86. Hao F, Tan W, Jiang L, Zhang L, Zhao X, Zou Y, et al. Do psychiatric patients experience more psychiatric symptoms during COVID19 pandemic and lockdown? A case-control study with service and research implications for immunopsychiatry. Brain Behav Immun. (2020) 87:100-6. doi: 10.1016/j.bbi.2020.04.069

87. Gullette EC, Blumenthal JA, Babyak M, Jiang W, Waugh RA, Frid DJ, et al. Effects of mental stress on myocardial ischemia during daily life. JAMA. (1997) 277:1521-6. doi: 10.1001/jama.1997.03540430033029

88. Dimsdale JE. Psychological stress and cardiovascular disease. J Am Coll Cardiol. (2008) 51:1237-46. doi: 10.1016/j.jacc.2007.12.024

89. Schwartz BG, French WJ, Mayeda GS, Burstein S, Economides C, Bhandari $\mathrm{AK}$, et al. Emotional stressors trigger cardiovascular events. Int J Clin Pract. (2012) 66:631-9. doi: 10.1111/j.1742-1241.2012.02920.x

90. Makwana N. Disaster and its impact on mental health: a narrative review. $J$ Fam Med Prim Care. (2019) 8:3090-5. doi: 10.4103/jfmpc.jfmpc_893_19

91. Kario K, McEwen BS, Pickering TG. Disasters and the heart: a review of the effects of earthquake-induced stress on cardiovascular disease. Hypertens Res. (2003) 26:355-67. doi: 10.1291/hypres.26.355

92. Hayman KG, Sharma D, Wardlow RD, Singh S. Burden of cardiovascular morbidity and mortality following humanitarian emergencies: a systematic literature review. Prehosp Disaster Med. (2015) 30:80-8. doi: 10.1017/S1049023X14001356

93. Bazoukis G, Tse G, Naka KK, Kalfakakou V, Vlachos K, Saplaouras A, et al. Impact of major earthquakes on the incidence of acute coronary syndromes - A systematic review of the literature. Hellenic J Cardiol. (2018) 59:262-7. doi: 10.1016/j.hjc.2018.05.005

94. Brooks SK, Webster RK, Smith LE, Woodland L, Wessely S, Greenberg $\mathrm{N}$, et al. The psychological impact of quarantine and how to reduce it: rapid review of the evidence. Lancet. (2020) 395:912-20. doi: 10.1016/S0140-6736(20)30460-8

95. Maas AHEM, Appelman YEA. Gender differences in coronary heart disease. Neth Heart J. (2010) 18:598-603. doi: 10.1007/s12471-010-0841-y

96. Flavahan NA. Atherosclerosis or lipoprotein-induced endothelial dysfunction. Potential mechanisms underlying reduction in EDRF/nitric oxide activity. Circulation. (1992) 85:1927-38. doi: 10.1161/01.CIR.85.5.1927

97. Hayashi T, Yamada K, Esaki T, Kuzuya M, Satake S, Ishikawa T, et al. Estrogen increases endothelial nitric oxide by a receptor-mediated system.
Biochem Biophys Res Commun. (1995) 214:847-55. doi: 10.1006/bbrc.199 5.2364

98. Nofer JR. Estrogens and atherosclerosis: insights from animal models and cell systems. J Mol Endocrinol. (2012) 48:R13-29. doi: 10.1530/JME-11-0145

99. Hajar R. Framingham contribution to cardiovascular disease. Heart Views. (2016) 17:78-81. doi: 10.4103/1995-705X.185130

100. Bairey Merz CN, Olson MB, McClure C, Yang YC, Symons J, Sopko $\mathrm{G}$, et al. A randomized controlled trial of low dose hormone therapy on myocardial ischemia in postmenopausal women with no obstructive coronary artery disease: results from the national institutes of health national heart, lung, and blood institute (NHLBI) - sponsored women's ischemia syndrome evaluation (WISE). Am Heart J. (2010) 159:987.e1-7. doi: 10.1016/j.ahj.2010.03.024

101. Hormone Therapy Heart Disease; Number 565. ACOG (2013). Available online at: https://www.acog.org/en/Clinical/Clinical Guidance/Committee Opinion/Articles/2013/06/Hormone Therapy and Heart Disease (accessed January 4, 2021).

102. Garcia M, Mulvagh SL, Merz CNB, Buring JE, Manson JE. Cardiovascular disease in women: clinical perspectives. Circ Res. (2016) 118:1273-93. doi: 10.1161/CIRCRESAHA.116.307547

103. Fish EN. The X-files in immunity: sex-based differences predispose immune responses. Nat Rev Immunol. (2008) 8:737-44. doi: 10.1038/nri2394

104. Pennell LM, Galligan CL, Fish EN. Sex affects immunity. J Autoimmun. (2012) 38:J282-91. doi: 10.1016/j.jaut.2011.11.013

105. Zuern CS, Lindemann S, Gawaz M. Platelet function and response to aspirin: gender-specific features and implications for female thrombotic risk and management. Semin Thromb Hemost. (2009) 35:295-306. doi: 10.1055/s-0029-1222608

106. Rauch U. Gender differences in anticoagulation and antithrombotic therapy. Handb Exp Pharmacol. (2012) 523-42. doi: 10.1007/978-3-642-30726-3_23

107. Haast RAM, Gustafson DR, Kiliaan AJ. Sex differences in stroke. J Cereb Blood Flow Metab. (2012) 32:2100-7. doi: 10.1038/jcbfm.2012.141

108. Moser Debra K, Kimble Laura P, Alberts Mark J, Alonzo A, Croft JB, Dracup $\mathrm{K}$, et al. Reducing delay in seeking treatment by patients with acute coronary syndrome and stroke. Circulation. (2006) 114:168-82. doi: 10.1161/CIRCULATIONAHA.106.176040

109. Anderson Beth E, Rafferty Ann P, Lyon-Callo S, Fussman C, Reeves MJ. Knowledge of tissue plasminogen activator for acute stroke among Michigan adults. Stroke. (2009) 40:2564-7. doi: 10.1161/STROKEAHA.108.545988

110. Rutledge T, Linke SE, Krantz DS, Johnson BD, Bittner V, Eastwood JA, et al. Comorbid depression and anxiety symptoms as predictors of cardiovascular events: results from the NHLBI-sponsored women's ischemia syndrome evaluation (WISE) study. Psychosom Med. (2009) 71:958-64. doi: 10.1097/PSY.0b013e3181bd6062

111. Rutledge T, Linke SE, Johnson BD, Bittner V, Krantz DS, Cornell CE, et al. Relationships between cardiovascular disease risk factors and depressive symptoms as predictors of cardiovascular disease events in women. $J$ Womens Health. (2012) 21:133-9. doi: 10.1089/jwh.2011.2787

112. Galbraith EM, Mehta PK, Veledar E, Vaccarino V, Wenger NK. Women and heart disease: knowledge, worry, and motivation. J Womens Health. (2011) 20:1529-34. doi: 10.1089/jwh.2010.2356

113. Lima BB, Hammadah M, Kim JH, Uphoff I, Shah A, Levantsevych $\mathrm{O}$, et al. Association of transient endothelial dysfunction induced by mental stress with major adverse cardiovascular events in men and women with coronary artery disease. JAMA Cardiol. (2019) 4:988-96. doi: 10.1001/jamacardio.2019.3252

Conflict of Interest: The authors declare that the research was conducted in the absence of any commercial or financial relationships that could be construed as a potential conflict of interest.

Copyright (C) 2021 Dhaibar and Cruz-Topete. This is an open-access article distributed under the terms of the Creative Commons Attribution License (CC BY). The use, distribution or reproduction in other forums is permitted, provided the original author(s) and the copyright owner(s) are credited and that the original publication in this journal is cited, in accordance with accepted academic practice. No use, distribution or reproduction is permitted which does not comply with these terms. 